\title{
The Philosophy of Science of Ferdinand Braun ${ }^{1}$
}

\author{
Alexander Pechenkin \\ Institute for the History of Science and Technology, \\ Russian Academy of Sciences \\ and Faculty of Philosophy, \\ Lomonosov Moscow State University, \\ Leninskie Gory, Moscow GSP-1 \\ E-mail:a_pechenk@yahoo.com
}

\begin{abstract}
The Nobel Prize winner Karl Ferdinand Braun has not left any considerable writings on the philosophy of science. Nevertheless, his philosophical excursions help us to understand his creative work in physics and the philosophical positions of his disciples. Braun emphasized the fundamental position of the so-called "integral laws" to which the law of conservation of energy belongs. He was a consecutive empiricist and emphasized the relativity of physical schemes and models with respect to experimental devices. In the style of some German physicists he proclaimed the oscillatory unification of the theory of electricity and optics.
\end{abstract}

Keywords: energetism, engineering, Kantianism, Machism, Naturphilosophie, radio-physics, the theory of oscillations

\section{Introduction}

The article discusses the philosophy of science in the writings of Karl Ferdinand Braun (1850-1918), professor of the Strasbourg University and the Nobel Prize winner. As this philosophy of science has never been presented systematically, it is essential to trace Braun's ideological evolution and to represent his activities as the leader of a group of scientists who made significant contributions to the development of radio. It is especially interesting to trace the historical lineage from Braun's philosophy of science to the philosophical essays of his Russian disciples Leonid Isaakovich Mandelshtam (1879-1944) and Nikolay

The article is supported by the Russian Humanities Research Foundation (RGNF) Project

No. 12-03-0641/12. 
Dmitrievich Papaleksi (1890-1947). Both held prominent positions in Soviet science and technology, and formed the core of a scientific community, generally called the Mandelshtam school.

\section{Biographical overview}

The biography of Karl Ferdinand Braun is described in two books. Friedrich Kurylo (1965; for an English version, see Kurylo, 1981) attempts to reintroduce Braun, wrongly forgotten, to the history of physics. Florian Hars (1999) has approached the topic from another angle and analyzes the reasons why Braun was later forgotten.

Braun followed a path typical for a German physicist of his time- from a university professor extraordinary and professor ordinary at a higher technological school to professor ordinary at a university. Braun was a student at the University of Marburg and the then University of Berlin, where Professor Georg Quincke (1834-1924) became his scientific supervisor. Georg Quincke conducted research in the areas of capillary phenomena, behavior of materials in electric and magnetic fields, and refraction of light. Even though Quincke's interferometer is sometimes mentioned in contemporary textbooks, he is mentioned even less often than Braun.

In 1877, Braun obtained his first academic position after he became extraordinary professor of mathematical physics at the University of Würzburg. In 1880, he obtained the same position at the University of Strasbourg under the lead of August Kundt. In 1883, he left Strasburg to take the position of professor ordinary at the Higher Technological School of Karlsruhe. In 1895, he returned to Strasbourg to become ordinary professor of experimental physics. In 1915, Braun left Strasbourg for the United States, where he died in 1918.

Like many physicists of the $19^{\text {th }}$ century, Braun was mostly an experimenter: he was involved in both fundamental and applied research, and even combined research in physics and chemistry. Braun's achievements are described in Orest Khvolson's textbook Kurs fizikii ('Course of physics', 1923), which was popular in Russia in the first decades of the $20^{\text {th }}$ century. Khvolson (1923a, pp. 629, 707; 1923b, pp. 531, 603-604, 624; 1923c, pp. 37, 150) points to eight results obtained by Braun. Among these, Khvolson describes the phenomenon of electrostenolysis (derived from the Greek root stenos which means 'narrow') discovered by Braun: if a current through certain electrolytic solutions is made 
to pass through a narrow slit in membrane wall, the slit begins to act as a third electrode (metal particles are deposited there and evolution of oxygen occurs). This discovery is also described in Kurylo's (1981, p. 71) book about Braun.

When Braun's name is mentioned in contemporary textbooks, it is usually done in connection with two discoveries-the Le Chatelier-Braun principle and the cathode-ray tube. According to what is generally known as Le Chatelier's principle, a change in a chemical system prompts an opposing reaction. In chemistry, this principle was discovered independently by Henry Louis Le Chatelier and Karl Ferdinand Braun. Braun came to this principle by studying the influence of pressure and temperature on solubility.

Braun constructed the first cathode-ray tube in 1897 and applied it, together with his students, in radio technological measurement. The title of his 1897 paper is 'On a method of demonstrating and studying the time dependence of variable currents'.

Braun's results in radio technology are not represented in contemporary textbooks on physics. Sometimes references to them are made in books on electronics. Even so, he was awarded the Nobel Prize in Physics for his research in radio (wireless telegraphy). This Nobel Prize was shared by two persons_-Karl Ferdinand Braun and Guglielmo Marconi (1909). Braun began to study radio after Marconi (18741937 ) by improving the transmitter invented by the latter in 1896 . However, as Braun's biography reveals, in all his reviews on radio engineering "he invariably started from Heinrich Hertz". Braun not only followed Marconi, he put research on the path to physical experiment and theory. He directly proceeded from the ideas of Hertz, who started to broadcast and receive radio signals in his laboratory as early as in 1887 by proceeding from the Maxwell's equations in electrodynamics. ${ }^{2}$

Hertz's transmitter went down in history as the Hertzian dipole. Two conductors are connected with an induction coil; these conductors went to meet each other and had two small balls at their ends. The induction coil produced the high voltage between the currents. A spark was generated between the balls and correspondingly produced electromagnetic oscillations in the system, emitting electromagnetic waves. Hertz also constructed a resonator to pick up the waves emitted by the dipole.

Proceeding from the ideas of his teacher Augusto Righi (1850-1920), Marconi increased the range of Hertz's dipole, and equipped this dipole with an antenna,

2 According to Jonathan Zenneck, Braun's former student and collaborator, "radio was discovered by Hertz and Popov. It is thanks to Marconi that we practically have wireless telegraphy". 
an electrode, placed at a certain height above the ground. In Germany, Marconi's experiments were reproduced by Adolf Slaby from the Technical University of Berlin-Charlottenburg, who introduced his improvements. As the historian of radio technology Vladimir M. Rodionov writes, "in early radio communication the typical scheme of transmitter sprang up: the scheme consisting of a highvoltage coil, power source, breaker, manipulator and radiating wire which is a frequency-specifying oscillatory system" (Rodionov, 1985, p. 115).

In 1898, Braun proposed an alternative scheme for the transmitter. He set up Marconi's circuit, but with the modification that had proved effective in improving the conduction telegraph: a primary coil in the oscillating circuit and a loosely coupled standard coil to transfer into the antenna-to-ground circuit.

In 1909, when receiving the Nobel Prize in Stockholm, Braun gave a lecture which was published in the Russian language by Mandelshtam and Papaleksi in 1910. In the Foreword to the lecture they wrote: ${ }^{3}$

Braun arrived at the conclusion that the problem of how to construct a powerful transmitter entailed two different problems: (1) how to generate high-frequency current, and (2) how to reach the rational radiation of electromagnetic waves. An antenna is a good radiator; however it is not efficient as a generator of high-frequency current. One first needs to get highfrequency current outside the antenna, then deliver it to the antenna which fulfils its task of radiating electromagnetic waves. The simple transmitter is not rational since its antenna is used as both a generator and a radiator. As a generator, Braun used a closed circuit. It resulted in alternating current which was transferred to the antenna [...] One of the advantages of such a division of functions is the possibility to reduce the unfavorable effect of the spark. [...] Braun's idea was the following. Upon the break of spark gap, rapid electric oscillations are generated in the closed circuit. These oscillations are transmitted to the antenna. After a period of time, most of the energy is concentrated in the antenna. Energy can not pass back to the closed circuit, since the spark is not able to transmit it. At this moment its unfavorable effect ceases. (Braun, 1910, p. vii)

Braun and his assistants improved the transmitter described above and in 1903, started his experiments with directed wireless telegraphy which would allow broadcasting to a selected region.

The Foreword is reprinted in Mandelshtam's Complete Works (1947-1955, vol. 3). 
Considering all the above, the question remains-why Braun, a Nobel Prize winner in physics, has been forgotten? Florian Hars (1999) attempts to explain it as follows: essentially Braun was a nineteenth-century physicist but he lived in the twentieth century. His main achievements are historically and logically connected with classical physics, the acme of which fell in the second half of the $19^{\text {th }}$ century. At the end of the century, physics was anticipating great future, while in the first decades of the $20^{\text {th }}$ century it was already experiencing these events. But Braun no longer participated in these.

As the majority of nineteenth-century physicists, Braun was a multi-disciplinary scientist. He contributed to many fields of physics and actively worked in the field of chemistry. In addition to Le Chatelier-Braun principle and the phenomenon of electrostenolysis, the famous five-volume book on the history of chemistry by Partington mentions the 'Braun reaction'. However, in the $20^{\text {th }}$ century, the physicists who delved deeply into one problem or into several interconnected problems were regularly successful. Besides, those who focused on atomic physics or on the problem of absolute and relative motion bore the palm.

In the second decade of the $20^{\text {th }}$ century, Braun pondered on his position in the field of physics and found it discomfiting. A paragraph in his letter to Zenneck from the $26^{\text {th }}$ of September, 1912, attests to that (Florian Hars has used it as the epigraph to his work).

By the way, I see that requirements abundantly and steeply rose. Those who did not deal with the principle of relativity, who did not read Sommerfeld's discussions in the cafe and were not be able to do other such things, lost... A technician only wants his money: this is simpler, this is the direct way. (Hars, 1999)

Braun meant the famous informal seminars organized by Arnold Sommerfeld as he became professor of theoretical physics at the Ludwig Maximilian University of Munich (Eckert, 1999, pp. 247-248). Among the seminar participants were Peter Debye, Werner Heisenberg, and Wolfgang Pauli.

However, Hars is not entirely correct in insisting on Braun being merely a hero of the past. Braun was a physicist who contributed much to technology. Integration of physics and technology in one institute was important to him. Braun can be considered as one of the originators of physico-technological research and physico-technological education and in this respect he can be regarded as a predecessor of twentieth-century science. 
In his lecture dedicated to the Kaiser's birthday, Braun (1899, p. 23) spoke about "the generations of thinkers and poets who would take the leading role in technology on the wave of national enthusiasm". As an curator of science he posed the problem more sharply. He not only guided the Strasbourg Institute for Physics towards radio technology, but also proposed that a sixth faculty was established in the structure of the University of Strasbourg - a faculty of technology (see Braun 1899, p. 23). This way he proposed to respond to the success of higher technological schools and start providing education in the new dynamic field of radio physics.

In his 1905 lecture, delivered before the board of full professors of the University of Strasbourg, Braun spoke about the fusion of pure and applied science.

Sometimes-especially in the last years-the idea to oppose pure science to applied research has taken the floor. For its high status natural science is indebted to its industrial applications. Here one makes sacrifices, this is justified. However, before applying something, one needs to have it. Usually priority is given to pure science. (Braun, 1905, p. 22)

Later in the Soviet Union, Mandelshtam and Papaleksi used the principle of the unity of fundamental and applied research in their rhetoric by reacting to the Soviet authorities' call to popularization of science.

The technological faculty, however, was not established within the framework of the University of Strasbourg. Higher technological schools were becoming increasingly influential in German science and education. They were recognized as equal with universities with respect to the academic degrees they offered.

In support of Florian Hars, however, it should be noted that Braun kept his distance from the modern idea of engineering physics. He tried to elevate radio engineering to the status of a discipline of physics. However, there was an alternative- to develop research in physics for the production of new effects. For example, Pyotr Leonidovich Kapitsa, worked at the Cavendish Laboratory in Cambridge under Ernest Rutherford in 1923-1925 and later in the Soviet Union, towards the same goal. 


\section{Braun's 1899 lecture: "integral laws" and Kantianism}

Hars referred to the philosophy of Braun, his main subject of research as eclectic in combining empirical criticism and Kantianism. This calls for an explanatory comment. There are no logical contradictions in Braun's philosophical detours. Braun formulated his philosophy of science with such caution that allowed him to later review the tendencies in the development of science and point to the problems that he considered to be essential.

Here we will focus on two lectures Braun, mentioned above, which he delivered at the University of Strasbourg. The first-in 1899-was held in honor of the birth of the Kaiser, the second took place in 1905, when Braun represented the University of Strasbourg as its rector.

The 1899 lecture was entitled 'Über Physikalische Forschungsart', which could be translated as 'On a kind of research (peculiar to) physics'. This lecture is imbued with the spirit of Kantian philosophy which is approached in a quite modernist manner and is rather loosely interpreted. Braun's lecture begins with an overview of the development of physics from Galileo and proceeds to Newton who developed a theory that would form the basis of textbooks, proposed a method for explanation in physics, and also proposed the idea to rely on forces of attraction between particles. It is interesting that Braun annotated this piece of Newton when his lecture was published. Braun contrasts Newton's method in the spirit of which electrical and magnetic phenomena were treated at the end of the $18^{\text {th }}$ and at the beginning of the $19^{\text {th }}$ century with the method of "integral laws" and treated the latter as more promising.

In Russian literature, the method of Newton is described as the 'method of molecular mechanics' (Pogrebysskii, 1966, pp. 118-132). This is a method of explaining physical phenomena by analogy with Newton's explanation of Kepler's laws and of tides. This explanation is based on the forces of attraction (and in some situations - of repulsion) acting between particles. These forces do not necessarily obey the inverse square law, and their action does not necessarily follow the three laws of Newton. Rather, the 'method of molecular mechanics' involves the formulation of new laws that would describe the action of attractive and repulsive forces between particles.

The Coulomb's law, the Ampère's law, and a number of rules describing chemical affinity were discovered and formulated within this framework. 
By chemical affinity it is understood as the force which manifests itself in chemical processes. This is a force of chemical interaction that is treated as an attraction of chemical elements' atoms. The peak of Newtonian theory of chemical affinity was the law of mass action, where the affinity (reaction rate) between two substances $\mathrm{A}$ and $\mathrm{B}$ is described as a product of 'mass action' (the concentrations of reacting substances $\mathrm{A}$ and $\mathrm{B}$ ), each raised to a particular power equal to a corresponding stoichiometric coefficient in the equation of the reaction (if $a A+b B=C$, the reaction rate is proportional to $\left.[A]^{a}[B]^{b}\right)$.

Braun used the predicate "integral" with respect to the laws which connect macroscopic magnitudes to each other. These laws do not apply to the forces acting among invisible particles. For Braun, the law of conservation of energy was an important example of the "integral law". In the spirit of some physicists who proclaimed energetism, Braun stated that "along with indestructible substance there is another constant magnitude, the energy of the universe" (Braun, 1899). ${ }^{4}$ According to Braun, the law of conservation of energy is based on facts and plays the role of a "regulative principle": it demands that in the course of natural processes the amount of total energy should remain constant.

In addition to the law of conservation of energy, Braun treats Faraday's law of electromagnetism as integral. In the view of Faraday's results it is possible to see the Maxwell equations. However, Braun spoke about Faraday's original observations and was not in touch with their proper mathematization. For Braun it was important that Faraday explained electric and magnetic phenomena by referring to the states of macroscopic substance, the electromagnetic field. By extrapolating Faraday's approach, Braun wrote that it would be incorrect to explain the fall of a stone by referring to the force of Earth's attraction. The field lines of Earth's gravitation explain this effect.

Braun did not reject any of the real methods and rather spoke in favor of pluralism. He emphasized that physics should not proceed from the generalization of empirical data and that research in physics presupposed "a skilful combination of facts". "The skilful combination of facts", Braun said, "provides a happy penetration to the essence (we characterize this penetration as intuition). This is a starting point of any research in any field" (Braun, 1899, p. 12)

Braun directly turned to Kant when he spoke about causality and cognizability of the world.

\footnotetext{
Under the term 'energetism' the history of philosophy combines different concepts which consider energy as a substance (either the only absolute substance, or, along with matter, one of two basic substances).
} 
We proceed from the principle of cognizability of nature. We also accept the concept of causality (although its meaning and range are under discussion). Although nature is not so far comprehended as a whole, all known facts are ordered in accordance with the categories of understanding and can be logically interpreted as cause and effect $[\ldots]$. According to the common use of the word, cause occupies the primary position in this one-to-one and reversible relation. We also expect that phenomena should be connected by not only qualitatively via logical laws, but also quantitatively, say, via the law of conservation of energy.

Thus, we establish a kind of integrity of spirit and nature. But we repudiate an interpretation of this integrity as an a priori construction of real phenomena by means of our spirit. By following Kant we postulate that our spirit is able to cognize the world of phenomena. However, we do not know a priori in which way new contents would fill our cognitive structures which by themselves are empty. We learn this by means of experience. If we are constructing a priori, we create a number of probable and possible universes which exist only logically and do not need to be real. Deductive research consists of constructing of a possible nature. Experience teaches us that a priori constructions seldom turn out corresponding to reality. (Braun, 1899, pp.16-18).

Braun speaks about the inclination of German spirit toward Naturphilosophie and hence toward a priori theorization. He also contrasts apriorism with the Newton-Faraday empirical method.

So, Braun accepted Kant's philosophy but rejected radical apriorism. For Braun, Kant's philosophy is rather a starting point for his own methodology. Scientific research is characterized by its method which could be changed under the pressure of empirical facts. For example, there is a method to proceed from the integral laws, say, the law of conservation of energy. However, this method is not absolute. Braun said,

And then I ask, how this aspiration for novelty (which is present in every person) paves its way? In other words, we know that nature has laws, for example, the law of conservation of energy which is confirmed by facts. However, we are able to imagine that we consciously seek and yet cannot find a confirmation to this principle. To do this would be enough, so we just did not notice some kind of substantial magnitude characterizing a small form of energy. If with Kant we assume that a thing in itself exists, a thing which may not be exhausted by its forms of expression that are appropriate to our 
cognitive abilities, then it is not surprising that we still give a quantity, and, in accordance with our logic, a value to a quantitatively essential element of the chain of transforming one into another forms of energy? Or is it just a coincidence? Are there other immanent laws of nature that we are, due to a lack of relevant organizations, never to learn? Why does our common sense try to escape from the latter assumption? (Braun, 1899, pp. 20-21)

Braun further points out that these issues are already present in the field of philosophy, especially metaphysics, which has attracted the attention of humanity for a long time, and in which there are no final answers. According to Braun, philosophy provides the necessary balance between "positive knowledge" and "unknown gloom" surrounding any new scientific problem. In contrast to philosophy, "positive knowledge", however, focused on practice.

Aber wie für transscendentale, so gibt die Naturforschung ihre Resultate auch ab zur Verwertung in ein nach der anderen Seite gelegenes Gebiet, das reale, der praktischen technischen Anwendung.

[However, with respect to the transcendental, scientific research provides its results for application on the other side of an adjoining area, actually in the field of practical technological activity](Braun, 1899, p. 22).

In other words, Braun, highly appreciating Kant's philosophy, distinguished between two principles of scientific inquiry-namely, the transcendental (mental designing) and the real (observation, experimentation, technical application). Both of these principles are in constant development and interaction. For Braun, as a representative of classical physics, cognizability of the world is connected with the implementation of the law of causality. Knowledge of the world is the knowledge of causal relationships, in which the transcendental cause and effect model is performed with experimental facts.

Braun, however, presupposed the relativity of scientific laws, even the relativity of such general law as the law of conservation of energy. This law is based on a mental scheme "in the transformation of qualitatively different forms of energy their quantitative equality is valid." This notional circuit is filled with factswith the results of measurements of energy. It directs the researcher to search for new forms of energy. If somewhere the equality of energies is violated, then some form of energy has not been taken into account. Yet situations are possible where the discrepancy between a thought scheme and empirical facts shows that the law of energy conservation becomes problematic. 
Braun took into account the situations where the thought schemes do not regulate empirical facts, the situations when possible worlds are being constructed: for example, the world where the law of conservation of energy is not true. However, as a physicist he was not interested in discussing such worlds. These are the worlds for philosophers. However, philosophy formulates the questions which allow us to determine what is not cognizable. These are questions of the following kind: is there an alternative physics which we never cognize because of the particular qualities of our mind and body?

\section{Braun's 1905 lecture and Machism}

The 1905 lecture was entitled 'On wireless telegraphy and new researches in physics'. This lecture is less philosophical than the one delivered in 1899. Braun showed an extensive retrospective of the development of radio-he mentioned Guglielmo Marconi, Marconi's company and his own work. At the end of the lecture, he came to two philosophical conclusions. The first concerns the unity of fundamental and of applied research (see the discussion in the previous section), the second was also partially cited and reads as follows:

New ways of research can not be designed a priori. As always, the fundamentally new problems presuppose fundamentally new methods. Atoms do not represent any ultimate reality or real $\alpha \tau 0 \mu \sigma \sigma-a l t h o u g h$ this is a firm belief. Apparently, there is no point in moving along beaten tracks. With bolts and levers we have no chance to penetrate into nature. Permanent and tenacious efforts - this is what could be helpful instead. Lucky discovery of a new relationship will bring us the right understanding. (Braun, 1905, p. 22)

As early as in 1899, Braun cautioned against Naturphilosophie and spoke about the relativity of all natural laws. In his 1905 lecture, the tenor of empirical criticism resonates more strongly. Braun analyzed the concept of homogeneity and showed this concept's relativity with respect to the experimental devices and correspondingly to the problems which a researcher set before him/her. He proposes the following view. There is a number of stone poles which are lined up with an interval comparable with their sizes. A train of electrical waves falls down on this line of stone poles. If the wavelength is the order of the width of stone poles, then the waves behave themselves like the waves of a river which met the 
piers of a bridge. The waves partially pass through the obstacle, partially fall back. If the wavelength surpasses the width of the stone poles, the view is different.

Now by their own size the waves do not perceive the small gaps in the line of stone poles, and this line behaves itself as a continuous wall which uninterruptedly and steadily fills up the space, it behaves itself as a homogeneous body (Braun, 1905, p. 14).

In terms of electric waves of $70 \mathrm{~cm}$ wavelength, a conglomerate consisting of bricks and gaps between them is a homogeneous body. To our sense organs this conglomerate appears different.

This relativity of physical schemes and models with respect to experimental devices became a favorite topic in the lectures of Mandelshtam and the philosophical essays of his disciples.

Having discussed the homogeneity of solid bodies, Braun turned his attention to the smallest particles. Having witnessed the splitting of the traditional atom, he dedicated himself to the mystery of radium, the element discovered in the process of research of uranium. However, Braun was a scrupulous experimenter and strongly advised to distinguish between fact and fiction.

We don't know this substance well enough and on closer examination startling phenomena turned out to be unprepossessing. The method of research of radioactivity involves an observation of the velocity with which the detecting foil (electroscope's plate) falls. This is our dry residue. (Braun, 1905, p. 21)

Here Braun is referring to Ernest Rutherford's famous experiments concerning the deviation of $\alpha$-rays in electric and magnetic fields (1902). Rutherford's rays, emitted from a layer of radium salt, were passed through a very thin aluminum plate and fell into a chamber where they ionized the hydrogen contained in it. The ionization was measured by the rate of the fall of the plate from the foil in the electroscope. If a horizontal magnetic field is created, the $\alpha$-rays were deflected toward the metal plates and absorbed by them. As a result, the less amount of particles come to the chamber, the smaller ionization they provide, and the foil in the electroscope falls more slowly.

The final section discusses Braun's relation to Ernst Mach (1838-1916). Although Braun allegedly was not a Machist, he sympathized and kept up correspondence with Mach since 1894. Braun joined the number of physicists and scientists 
who, between 1910 and 1914, nominated Ernst Mach for the Nobel Prize in Physics. Braun's nomination letter indicated that as the Nobel Prize might soon be awarded for the new theory of space and time, it should first be given to Mach, an early advocate of these ideas, and a leading experimental physicist. Braun also insisted on Mach's wider influence via his "philosophical explications" and "his clear, profound historical-physical studies" (The letters to the Nobel Prize Committee on behalf of Mach from Braun and other prominent physicists are published in Blackmore \& Hentschel, 1985). ${ }^{5}$ In his letter Braun wrote that Mach proposed a "strict idea of how our fundamental physical concepts were being formed" and, "from the point of view of the theory of cognition, answered the question what our definitions of physical concepts meant".

As noted above, the Braun's sympathy for Mach did not mean his devotion to Mach's philosophy. However in German physics, Mach's ideas were becoming commonly held. For example, young Papaleksi's synopsis includes a sentence which is basically a quotation from Mach's Mechanics-this is about Galileo Galilei who redirected the study of free fall from the question 'why?' to 'how?' and a comment that in physics one should describe empirical facts rather than look for explanations (ARAN, 1939).

However, Braun was very careful in his philosophical statements. Like many other physicists of his time he pointed to the danger of falschen Naturphilosophie in physics. In contrast to some authors who were inclined to regard energy as a substance, Braun treated the law of conservation of energy as regularity, though not a normative principle (Braun, 1899, pp. 19-21). Without any substance as an end of cognition it is up to us to search for a "successful combination of facts".

\section{The Nobel Lecture and the oscillatory unification of science}

In his Nobel Lecture, Braun spoke about his contribution to radio physics and radio engineering, and his achievements for which he had received the Nobel Prize. He did not touch specifically upon fundamental philosophical problems. However, philosophy was present in his Nobel Lecture, and quite rightly so, because Braun took into consideration an extensive retrospective of the development of physics. This was the philosophy of the unity of electrical and optical phenomena taken as oscillatory phenomena. Having described his

Among those who sent letters to nominate Mach were also Hendrick Lorentz and Wilhelm Ostwald, see Blackmore \& Hentschel, 1985 and Holton, 1992. 
achievements in directional radiotelegraphy where the molecular oscillators excited by the antenna's radiation are essential, Braun (1909) said the following:

If nowadays optical phenomena are ascribed to electrical molecular resonators, then electrical processes, as demonstrated here by a single example, can also be linked up with optical phenomena, though this can hardly be experimentally verified in this field.

Here, the study of electrical oscillations supplements that of optical oscillations, and since we are in the position to tackle a problem in either field by analogy with a phenomenon which is comprehended in the other field, the first attack on the problem can be made from the electrical or the optical standpoint according to whichever presents the easier concept to realize. (Braun, 1909, p. 241)

The oscillatory unification of different fields of physics was practically realized at the institute headed by Braun. In this connection Nikolay Papaleksi writes in his biography of Mandelshtam:

The atmosphere of electromagnetic oscillations, in which Leonid Isaakovich found himself by entering into scientific life, has played the great part in formatting the basic lines of his scientific activity and has determined the "oscillatory approach" which was significant for his creative work. (Mandelshtam, 1947-1955, p. 14)

Zenneck, who was Braun's first assistant at the Institute of Physics when Mandelshtam started at this institute, declared something along similar lines. From Zenneck's Recollections it follows that Rayleigh's The Theory of Sound (1891) was popular at Braun's institute (Zenneck, 1961, p. 102). In spite of the fact that its title suggests that this is a study of acoustics, it is a fundamental source on the theory of oscillations. Papaleksi emphasized that The Theory of Sound was of seminal importance in Mandelshtam's education. Mandelshtam biographers correlate his "oscillatory approach" elaborated in Strasbourg with his Moscow ideology of oscillations.

As early as in Strasbourg Mandelshtam scrutinized closely the classical theory of oscillations. The main source was Rayleigh's two-volume book The Theory of Sound and a large body of his papers. Mandelshtam inherited Rayleigh's linear oscillatory culture and he did his best to transmit this culture to subsequent generations. [...] However, Mandelshtam was not merely Rayleigh's successor in the field of linear oscillations. Under his guidance 
a new scientific area emerged and obtained widespread recognition. This area is connected with research into nonlinear oscillations. (Mandelshtam, 1947-1955, p. 40)

It is worth mentioning that Braun's idea about the "oscillatory unification" coincided with the trend peculiar to German science-the trend toward the development of unified technological studies in the area of oscillations (Barkhausen, 1932; Hort, 1910) and in general toward the theory of oscillations unifying mechanics and the theory of electricity (Fürth, 1920).

\section{References}

ARAN (1939), Papaleksi, Nikolay Dmitrievich (1880-1947), fizik. spetsialist v oblasti radiofiziki i radiotekhniki, akademik AN SSSR, ARAN 600, op. 1, d.12, Archives of the Russian Academy of Sciences.

Barkhausen, H. (1932), Einführung in die Schwingungslehre, Leipzig: Verlag von S. Hirzel.

Blackmore J. T. \& Hentschel, K., eds. (1985), Ernst Mach als Außenseiter, Vienna: Wilhelm Braunmueller.

Braun, K. F. (1899), Über physikalische Forschungsart, Strassburg: UniversitätsBuchdruckerei von J. H. Ed. Heitz.

— (1905), Über drabtlose Telegraphie und neuere physikalische Forschungen, Strassburg: Universitäts-Buchdruckerei von J. H. Ed. Heitz.

- (1909), 'Electrical oscillations and wireless technology,' Nobel Lecture, 11 December 1909, pp. 227-245. Retrieved from http://www.nobelprize.org/nobel_ prizes/physics/laureates/1909/braun-lecture.pdf [accessed Dec 2012]

Eckert, M. (1999), 'Mathematics, Experiment, and Theoretical Physics: The Early Days of the Sommerfeld School,' Physics in Perspective, vol. 1 (1999), pp. 238-252. http://dx.doi.org/10.1007/s000160050021

Fürth, R. (1920), Schwingungserscheinung in der Physik, Braunschweig: Vieweg und Sohn.

Hars, F. (1999), Ferdinand Braun (1850-1918): Ein wilhelminischer Physiker, Berlin: Diepholz.

Holton, G. (1992), Ernst Mach and the Fortunes of Positivism in America,' ISIS, vol. 83, pp. 27-60. http://dx.doi.org/10.1086/356024

Hort, W. (1910), Technische Schwingungslehre, Berlin: Julius Springer. 
Khvolson, O. D. (1923a), Kurs fiziki (Physics Course), Vol. 2, Berlin: Gosudarstvennoie izd-vo.

— (1923b), Kurs fiziki, Vol. 4, Berlin: Gosudarstvennoie izd-vo.

- (1923c), Kurs fiziki, Vol. 5, Berlin: Gosudarstvennoie izd-vo.

Kurylo, F. (1965), Ferdinand Braun. Leben and Wirken des Erfinders der Braunschen Röhre-Nobelpreisträger 1909, München: Heinz Mooz Verlag.

Kurylo, F. \& Susskind, Ch. (1981), Ferdinand Braun: A Life of the Nobel Prizewinner and Inventor of the Cathode-Ray Oscilloscope, Cambridge, MA: The MIT Press. PMid:6801201

Mandelshtam, L. I. (1947-1955), Complete Works, [In Russian] Vols. 1-5, Moskva: izd-vo. AN SSSR.

Pogrebysskii, I. B. (1966), Ot Lagranga k Einsteinu (From Lagrange to Einstein), Moscow: Nauka.

Rodionov, V. M. (1985), Zarozhdenie radiotekhniki, Moscow: Nauka.

Zenneck, J. (1961), Erinnerungen eines Physikers, München: Deutches Museum.

Alexander Pechenkin graduated from the Mendeleev Institute of Chemistry and Technology (Faculty of Organic Substances) and the Lomonosov Moscow State University (Faculty of Mechanics and Mathematics). He received his PhD from the Institute of Philosophy of the Academy of Sciences in 1968. $\mathrm{He}$ is Professor of the Moscow State University and delivers courses in the history and philosophy of science. He also works for the Institute for the History of Science and Technology of the Russian Academy of Sciences. 